\title{
Energy Requirements of the Switchable Polarity Solvent Forward Osmosis (SPS-FO) Water Purification Process
}

\author{
Daniel S. Wendt, Christopher J. Orme, Gregory L. Mines, and Aaron D. Wilson \\ Idaho National Laboratory, P.O. Box 1625 MS 3732, Idaho Falls, ID 83415-3732, USA \\ aaron.wilson@inl.gov, voice (208) 526-1103
}

\begin{abstract}
A model was developed to estimate the process energy requirements of a switchable polarity solvent forward osmosis (SPS FO) system for water purification from aqueous $\mathrm{NaCl}$ feed solution concentrations ranging from 0.5 to 4.0 molal at an operational scale of $480 \mathrm{~m}^{3} /$ day (feed stream). The model indicates recovering approximately $90 \%$ of the water from a feed solution with $\mathrm{NaCl}$ concentration similar to seawater using SPS FO would have total equivalent energy requirements between 2.4 and $4.3 \mathrm{kWh}$ per $\mathrm{m}^{3}$ of purified water product. The process is predicted to be competitive with current costs for disposal/treatment of produced water from oil and gas drilling operations. Once scaled up the SPS FO process may be a thermally driven desalination process that can compete with the cost of seawater reverse osmosis.
\end{abstract}

\section{INTRODUCTION}

Previously our group introduced switchable polarity solvents (SPS) [1-3] as a draw solution for forward osmosis (FO) [4]. The SPS FO process has the potential to treat very high concentration solutions; the process has already been demonstrated to provide positive FO flux against a $\mathrm{NaCl}$ solution at 5 molal or 226,000 ppm total dissolved solids (TDS) [4]. As a thermally driven process SPS FO may be a more cost effective than electrically driven processes, such as reverse osmosis (RO), even if more energy is required. Heat energy is approximately a tenth the cost of electricity per unit energy so even 
with a lower energy efficiency SPS FO is expected to have a low cost. FO also offers potential reduced fouling issues and pretreatment requirements when compared to RO Pretreatment costs are often $60 \%$ of the cost to treat oil and gas water with RO versus the core hydraulic RO energy requirements contributing only $\sim 20 \%$ of the total treatment cost.. The SPS FO system also has the potential to be driven by lowgrade heat source which can be obtained at great discount in the form of waste heat from an industrial process.

The SPS class of solvents is capable of switching between an aprotic non-ionic form, to a water soluble ionic liquid/solute through the introduction and removal of $\mathrm{CO}_{2}$ (Equation 1).

$$
\mathrm{NR}_{3(\text { org })}+\mathrm{CO}_{2(\mathrm{~g})}+\mathrm{H}_{2} \mathrm{O} \rightleftharpoons \mathrm{HNR}_{3}^{+}{ }_{(\mathrm{aq})}+\mathrm{HCO}_{3 \text { (aq) }}^{-}
$$

The ionic form can act as a draw solute in an FO process and then be separated from the product water through the application of heat; the heat driving off carbon dioxide and generating the waterimmiscible aprotic tertiary amine. SPS is an example of a growing number of switchable thermolytic and thermal sensitive solutes [5-14]. Our initial demonstration of the SPS FO process used dimethylcyclohexylamine (DMCA) [4]. While DMCA is a potential SPS draw solute an SPS optimized for SPS FO process has been sought [15-18] and suggest 1-cyclohexylpiperidine is an especially promising candidate. Regardless of the SPS employed in the process DMCA is an excellent model SPS and was used to develop the process energy model.

While SPS FO appears promising in terms of energy requirements and process costs, a rigorous evaluation had not been conducted. In the following text, a process model is developed to estimate the SPS FO process energy requirements and capital and operating costs similar to work done during the development of the ammonia- $\mathrm{CO}_{2}$ draw system [19]. This model was a prerequisite for pursuing the SPS FO concept further than demonstration of process components and will be used to guide the integration and development of scale demonstrations and pilot systems. 
The model was used to investigate two potential applications for SPS FO technology:

desalination and treatment of produced waters from oil and gas drilling operations. While there is some variation in the range of temperature and salinity values typical of seawater desalination feed streams, these variables can vary considerably for produced water treatment applications. Produced water generally exits oil and gas wells at temperatures greater than ambient. The salinity of produced water may vary from levels similar to that of drinking water to several times more saline than sea water [20]. The process model was implemented to analyze the effect of feed water stream temperature and composition on process energy requirements and product yield.

Since SPS FO process thermal energy requirements can be met using low grade heat, an elevated temperature produced water feed stream could be utilized as the heat source for supplying SPS FO process thermal energy demands. Depending on the feed water stream temperature, several different SPS FO process heat integration schemes could be utilized. Three scenarios, each with different heat integration schemes, were investigated to evaluate the energy requirements and costs associated with processing feed water streams supplied over a range of temperatures. Scenario 1 is applicable for situations where the feed water stream is supplied at temperatures similar to ambient such that thermal energy input to meet process heat demands must be provided by an external heat source. Scenario 2 is applicable when the feed water stream is supplied at a temperature sufficient to provide the process thermal energy input. Scenario 3 is applicable in situations where the feed stream temperature is sufficiently high to provide heat input to an organic Rankine cycle (ORC) power cycle in addition to SPS FO process thermal energy input.

\section{PROCESS MODEL AND ASSUMPTIONS}

A basic process flow diagram of the SPS FO process is provided in Figure 1. An Aspen Plus process flow diagram with the major process components from the basic process flow diagram highlighted is included as Figure 2. Non-highlighted items include compressor/pumps, heat exchangers, valves, etc. required to adjust the process conditions of the flow in and out of the major components. 
Many of the process energy requirements are associated with the ancillary process components that function in support of the major components.

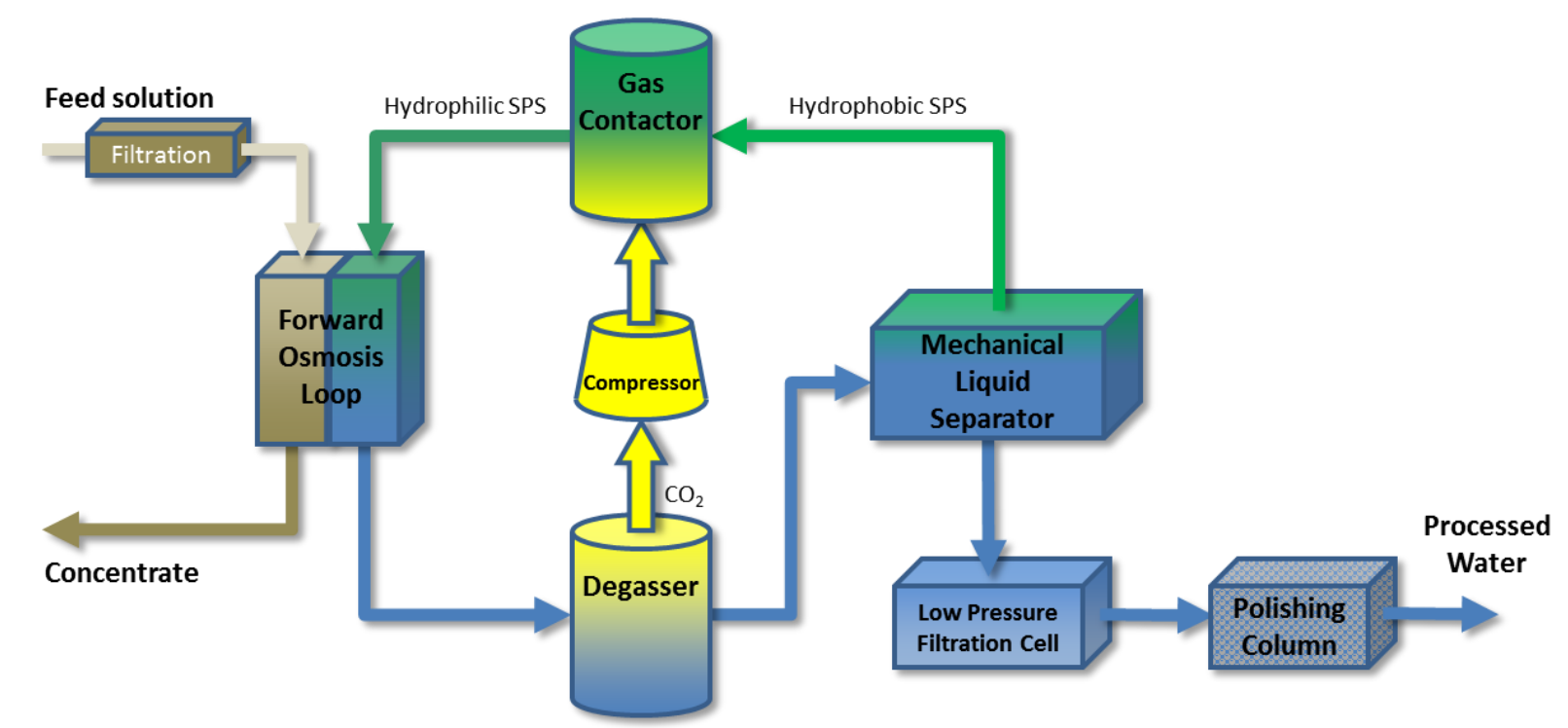

Figure 1. The proposed switchable polarity solvent forward osmosis (SPS FO) process.

The SPS FO process simulation was performed using a feed water stream volumetric flow rate basis of $20 \mathrm{~m}^{3} / \mathrm{hr}$. The feed water stream pressure was set to a value equal to that of the concentrated draw stream exiting the gas contactor such that there is no hydraulic pressure differential across the FO membrane. The feed water stream was simulated as an aqueous $\mathrm{NaCl}$ stream with concentration ranging from 0.5 to 4.0 molal $(28,400-189,500 \mathrm{ppm}$ TDS), which brackets the feed water salinity typical of most desalination and produced water treatment applications. The feed water stream temperatures evaluated in this analysis vary according to the assumptions of each of the three scenarios evaluated. 


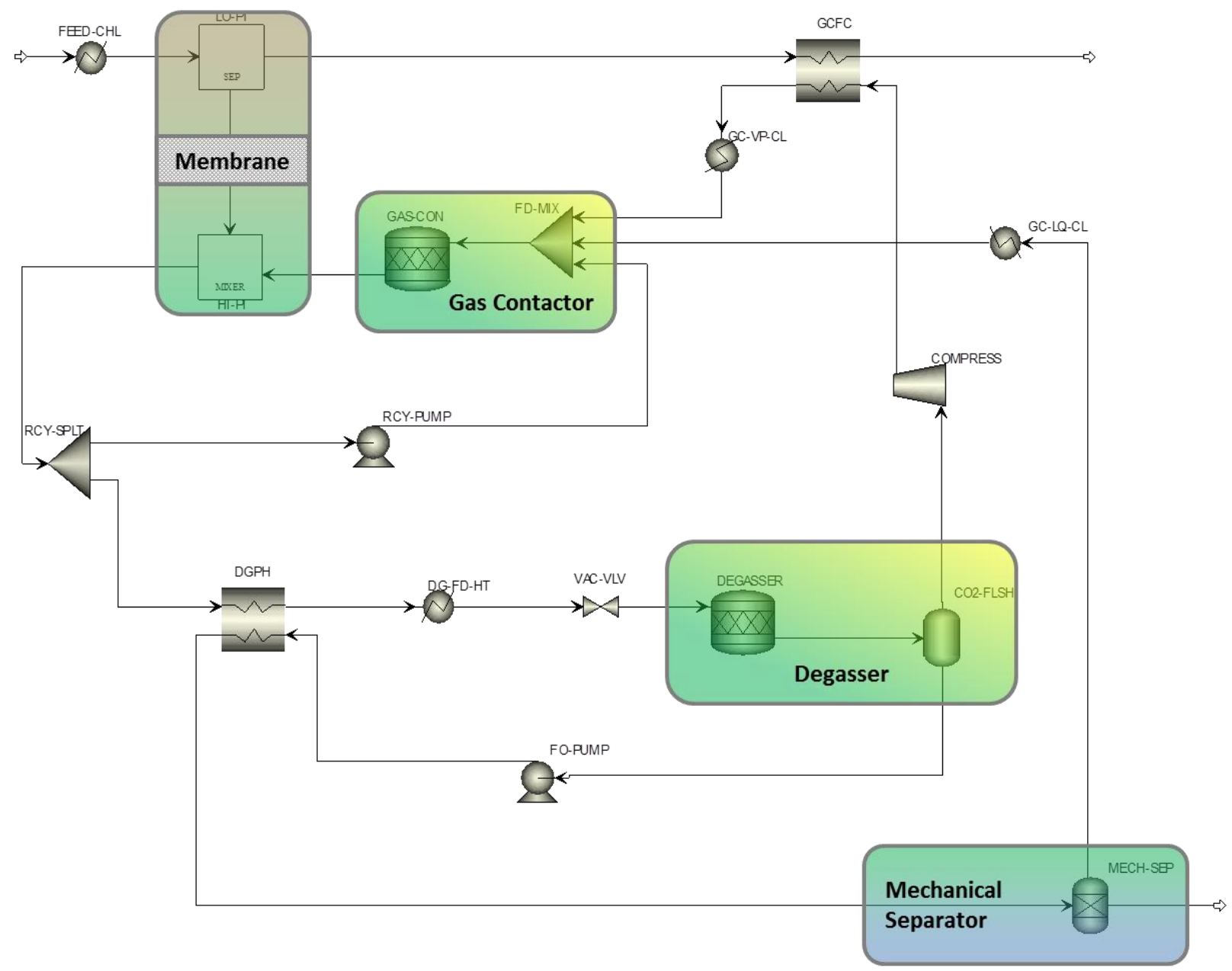

Figure 2. SPS FO process flow diagram used for processes modeling.

The SPS FO process energy requirements were analyzed using Aspen Plus V7.3 with the Unsymmetric Electrolyte NRTL property method (ENRTL-RK). The ENRTL-RK property method was utilized such that the electrolyte chemistry and properties of the process feed and internal streams could be computed. The SPS FO process chemistry included in this analysis is provided in Table 1. Reactions 1, 2, and 3 are electrolyte equilibrium reactions that are valid throughout all process unit operations where these components exist in the liquid phase. Reaction 4 is the aqueous SPS formation reaction that takes place in the gas contactor. Reaction 5 is the bicarbonate decomposition reaction, which takes place in the degasser and is the reverse of Reaction 4. 
Table 1. SPS FO process chemistry.

\begin{tabular}{|l|l|l|l|}
\hline Rxn No. & Specification Type & Stoichiometry & Unit operations \\
\hline 1 & Equilibrium & $\mathrm{H}_{2} \mathrm{O}+\mathrm{HCO}_{3}^{-} \rightleftharpoons \mathrm{CO}_{3}{ }^{2-}+\mathrm{H}_{3} \mathrm{O}^{+}$ & global \\
\hline 2 & Equilibrium & $2 \mathrm{H}_{2} \mathrm{O}+\mathrm{CO}_{2} \rightleftharpoons \mathrm{HCO}_{3}{ }^{-}+\mathrm{H}_{3} \mathrm{O}^{+}$ & global \\
\hline 3 & Equilibrium & $2 \mathrm{H}_{2} \mathrm{O} \rightleftharpoons \mathrm{OH}^{-}+\mathrm{H}_{3} \mathrm{O}^{+}$ & global \\
\hline 4 & Conversion & $\mathrm{C}_{8} \mathrm{H}_{17} \mathrm{~N}+\mathrm{CO}_{2}+\mathrm{H}_{2} \mathrm{O} \rightarrow \mathrm{C}_{8} \mathrm{H}_{17} \mathrm{NH}^{+}+\mathrm{HCO}_{3}{ }^{-}$ & gas contactor \\
\hline 5 & Conversion & $\mathrm{C}_{8} \mathrm{H}_{17} \mathrm{NH}^{+}+\mathrm{HCO}_{3}{ }^{-} \rightarrow \mathrm{C}_{8} \mathrm{H}_{17} \mathrm{~N}+\mathrm{CO}_{2}+\mathrm{H}_{2} \mathrm{O}$ & degasser \\
\hline
\end{tabular}

The Aspen Properties V7.3 component databanks do not include properties for the protonated DMCA molecule (referred to as $\mathrm{C}_{8} \mathrm{H}_{17} \mathrm{NH}^{+}$or $\mathrm{DMCAH}^{+}$). The bicarbonate formation and decomposition reactions account for a significant portion of the process thermal energy requirements. In order to compute the SPS FO process stream compositions and reactor energy requirements, a user defined $\mathrm{DMCAH}^{+}$component was defined with the parameters included in Table 2 and the molecular structure illustrated in Figure 3.

Table 2. Values assumed for DMCAH+ pure component scalar parameters.

\begin{tabular}{|l|l|l|}
\hline Parameter & Units & Value \\
\hline Normal Boiling Point & ${ }^{\circ} \mathrm{C}$ & 161.399 \\
\hline Molecular Weight & & 128.229 \\
\hline $\begin{array}{l}\text { Standard Specific Gravity at } \\
60^{\circ} \mathrm{F}\end{array}$ & 0.866 \\
\hline Ionic Charge Number & meter & 1 \\
\hline Born Radius of Ionic Species & $1.0 \times 10^{-10}$ \\
\hline $\begin{array}{l}\text { Ion Type for the Criss-Cobble } \\
\text { aqueous infinite dilution ionic } \\
\text { heat capacity equation }\end{array}$ & bar & $\begin{array}{l}-1.0 \times 10^{20} \text { (specification } \\
\text { recommended in Aspen Plus } \\
\text { documentation for ionic species } \\
\text { not present in vapor phase) }\end{array}$ \\
\hline $\begin{array}{l}\text { Extended Antoine vapor pressure } \\
\text { coefficient }\end{array}$ &
\end{tabular}

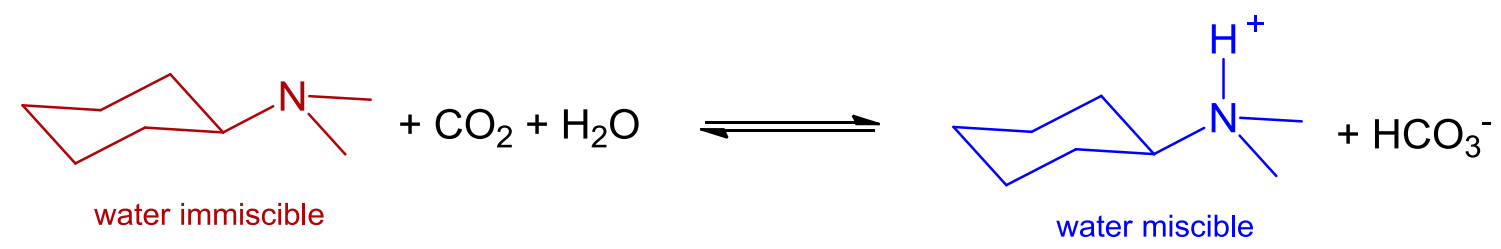

Figure 3. DMCAH+ structure and equilibrium with DMCA. 
In addition to the component property data parameters listed in the preceding discussion, Aspen Plus V7.3 property databanks do not include heat of formation data for $\mathrm{DMCAH}^{+}$. A design spec was configured to vary the $\mathrm{DMCAH}^{+}$heat of formation to match the bicarbonate decomposition reaction enthalpy reported by Tan [21]. This approach was possible as the heat of formation for all other reactants was included in the Aspen property databanks. The Aspen Plus property estimate system was used to estimate other $\mathrm{DMCAH}^{+}$temperature-dependent properties necessary for computing process mass and energy balances, including heat capacity, molar density, thermal conductivity, and viscosity.

Due to unavailability of equilibrium or kinetic data for Reactions 4 and 5, this analysis assumes that the bicarbonate formation and decomposition reactions proceed to completion in the gas contactor and degasser, respectively. For the purposes of this model this assumption is reasonable based on results from initial laboratory testing. It is expected that subsequent SPS FO process analyses will obtain and incorporate SPS reaction kinetic data to permit evaluation of reaction extent as a function of temperature and pressure in order to improve the estimates of gas contactor and degasser operating conditions and performance.

\subsection{Gas Contactor}

DMCA, $\mathrm{CO}_{2}$, and water are combined in the gas contactor, where process conditions are adjusted such that the concentrated aqueous SPS draw solution stream can be produced. The concentrated aqueous SPS draw solution exiting the gas contactor is adjusted to $77 \mathrm{wt} \% \mathrm{DMCAH}^{+}$and $\mathrm{HCO}_{3}{ }^{-}$by manipulating the SPS dilute recycle stream flow rate. This is very near the saturation point of a $\mathrm{DMCAH}^{+} \mathrm{HCO}_{3}{ }^{-}$ solution. Draw solutions with lower concentration have reduced osmotic pressure, which in turn reduces the flux of water from the feed stream. Additionally, lower concentration draw solutions will result in a lower water carrying capacity and increased circulation of water in the SPS FO primary process loop, which would have the effect of increasing SPS FO process costs and energy requirements as a result of increased process equipment size, pumping requirements, as well as fluid heating and cooling 
requirements. High concentration solutions suffer from higher viscosities [16], increasing pumping costs, and reduced mass transfer properties hindering flux kinetics given the thermodynamic driving force. Further experiments are required to find the optimal balance between high-concentration high-osmotic pressure high-carrying capacity and reduced viscosity and better mass transport properties. For the current analysis $77 \mathrm{wt} \%$ is a suitable assumption.

The gas contactor operating temperature is set to $25^{\circ} \mathrm{C}$ to provide a concentrated draw solution stream at a temperature compatible with FO membrane operating requirements and to achieve concentrated SPS solution with the desired composition (higher temperatures reduce the solubility of the $\mathrm{CO}_{2}$ reactant and favor the bicarbonate decomposition reaction, both of which negatively impact the concentration of the SPS draw solution that can be maintained). Since the reactions occurring in the gas contactor are primarily exothermic, it is expected the gas contactor will require active cooling. The gas contactor operating pressure is set to a value slightly above atmospheric pressure to enhance the solubility of $\mathrm{CO}_{2}$ in the liquid phase and to provide the pressure differential required to overcome the pressure drop of the various downstream process components such that the degasser will operate at atmospheric pressure. The gas contactor operating pressure is correlated to the temperature-dependent Henry coefficient for $\mathrm{CO}_{2}$ solubility in water such that at higher gas contactor operating temperatures higher operating pressure is required.

The gas contactor is modeled in Aspen Plus as a combination of a MIXER block and an RSTOIC stoichiometric reactor block. The bicarbonate formation reaction chemistry and reaction conversion is defined in the gas contractor RSTOIC block. Three Aspen Plus design specs are used to manipulate the gas contactor feed streams to achieve the target draw solution stream composition and flow rate. The purpose of each of these design specs is: (1) vary the DMCA circulation rate to achieve the desired membrane water flux, (2) vary the $\mathrm{CO}_{2}$ circulation rate to achieve the correct stoichiometric excess of $\mathrm{CO}_{2}$ in the gas contactor, and (3) vary the dilute draw recycle stream flow rate to achieve the correct draw solution concentration. 


\subsection{FO membrane unit}

The FO membrane unit is a semi-permeable membrane that selectively allows water permeation while retaining, and concentrating, impurities in the feed stream. Water in the feed stream is drawn through the semi-permeable membrane by the osmotic pressure differential resulting from the high concentration of switchable polarity solvent draw solution on the permeate side of the membrane. Water flow through the FO membrane results in the dilution of the draw solution.

The percentage of the feed water stream that permeates the FO membrane is a function of the osmotic pressure differential and the feed and draw stream flow rates. Feed stream and draw solution osmotic pressure were calculated using the methods we previously described [22]. This analysis assumes countercurrent flow with the quantity of water permeating the membrane determined by the osmotic pressure differential of the dilute draw solution relative to the feed water stream. The flow rate of the concentrated draw stream exiting the gas contactor was manipulated to achieve the permeate flux necessary to concentrate the feed water retentate stream to the saturation concentration.

The FO membrane is modeled in Aspen Plus as a combination of SEP separator and MIXER blocks. The permeate flow rate is computed as a function of feed and draw stream flow rates and the osmotic pressure gradient. The feed and draw stream osmotic pressures are calculated by multiplying the concentrations of each stream (molal basis) by the corresponding van't Hoff indices ( 2.09 for $\mathrm{NaCl}$ and 1.72 for DMCA). The permeate flow rate is varied using an Aspen Plus design spec such that the osmotic pressure of the dilute SPS stream exceeds that of the feed stream as indicated in Equation 2.

$$
\Pi_{\text {draw }}[\mathrm{Osm}]=1.2 \cdot \Pi_{\text {feed }}[\mathrm{Osm}]+1.0 \mathrm{Osm}
$$

This relationship is applied at the dilute end of the FO unit where the dilution of the SPS solvent is greatest to ensure that positive flux of water through the FO membrane is maintained at all operating conditions. The factor of 1.2 ensures that the draw stream osmotic pressure always exceeds that of the 
feed stream by a minimum of $20 \%$ over all concentration ranges. The fixed offset of 1.0 Osmolality units ensures that sufficient osmotic pressure driving force is present even at low feed stream concentrations. As experimental data becomes available at various concentrations this relationship will be modified or replaced.

As the focus of this analysis is primarily on SPS FO process energy requirements, the analysis did not include rigorous evaluation of FO membrane solute permeability. The membrane was assumed to operate with a rejection coefficient of unity; process operation at lower membrane rejection coefficients will have negligible effect on process energy balances, but would affect the long term management of the draw solute.

\subsection{Degasser}

The dilute draw stream exiting the membrane unit is sent to the degasser, where bicarbonate decomposition reactions liberate $\mathrm{CO}_{2}$ from the SPS FO solvent to change the dilute SPS liquid to a chemical form that is immiscible with water. The primary thermal energy requirements of the SPS FO process are associated with energy input into the degasser to provide the heat required to drive the endothermic bicarbonate decomposition reactions. A degasser preheater is included in the process to recover heat from the degasser liquid outlet stream. Our work has shown that switchable polarity solvents can be expected to have regeneration temperatures in the range of $60-80^{\circ} \mathrm{C}$ under atmospheric pressure conditions [17]. As there remains some level of uncertainty as to what the optimal degasser operating temperature will ultimately be, the process energy requirements in this analysis are reported for both degasser operating temperatures to bracket the expected range of results. $\mathrm{As}_{\mathrm{CO}_{2}}$ is produced by the bicarbonate decomposition reaction, regeneration temperatures at the lower end of this range may require partial vacuum conditions to enhance the rate of the regeneration process. This analysis assumes a degasser outlet pressure specification of 0.8 bar. 
The heat exchange process between the degasser feed stream and liquid product stream is modeled using and MHEATX block with a specified minimum internal temperature approach. The temperature and pressure of the degasser feed stream are subsequently adjusted to the required values using HEATER and a VALVE blocks. The degasser is modeled as an RSTOIC stoichiometric reactor and a FLASH2 block. The bicarbonate decomposition reaction chemistry and reaction conversion is defined in the RSTOIC block while the FLASH2 block is used to separate the vapor and liquid degasser products. A design spec is utilized to manipulate the outlet temperature of the degasser to the required temperature by varying the degasser heat input. The degasser thermal energy input, which increases the reactant temperature as well as provides the heat duty to drive the endothermic bicarbonate decomposition reaction, is then removed from the heat source specified in the scenario under investigation (external heat source or elevated feed stream).

\section{$2.4 \mathrm{CO}_{2}$ Vapor Recycle and Compression}

The $\mathrm{CO}_{2}$ vapor stream exiting the degasser is compressed and recycled to the gas contactor for reuse. This vapor stream exits the degasser at the specified regeneration temperature, and the temperature is further increased upon compression. Cooling the vapor prior to sending it to the gas contactor will reduce gas contactor active cooling requirements and potentially improve the absorption of $\mathrm{CO}_{2}$ into the gas contactor liquid phase. This analysis utilizes the concentrated feed water retentate stream (which exits the FO membrane at $25^{\circ} \mathrm{C}$ ) for cooling the gas contactor vapor inlet stream. This heat exchange operation is included as it increases the overall energy efficiency of the process.

\subsection{Mechanical Separator}

The mixed organic and aqueous phase liquid stream exiting the degasser and degasser preheater flows into the mechanical separator where the immiscible liquid phases separate with no additional energy input (gravity separation). The organic DMCA phase is recycled to the gas contactor for 
regeneration of the concentrated draw solution. The mechanical separator is modeled as an Aspen Plus SEP block.

This analysis assumes a complete separation of the aqueous and organic phases in the mechanical separator. While the organic amine will phase separate, in practice there will be trace ammonium and bicarbonate dissolved in the aqueous phase. These ions will remain in the product water, post mechanical separator, along will with trace amine and will be addressed with a low pressure, low energy consumption RO polishing process not explicitly addressed in this study. The assumption of complete aqueous and organic phase separation has minimal impact on process energy requirements as entrained water in the organic phase could be offset by decreasing the dilute draw solution recycle stream flow rate (such that the concentrated draw solution concentration is maintained at the target value) and entrained draw solution in the product water stream would be captured by the RO polishing step (which would also increase product purity and minimize draw solution replacement costs).

\subsection{Air-Cooler}

The SPS FO process energy analysis was evaluated at an ambient design temperature of $10^{\circ} \mathrm{C}$. Process energy requirements include use of an air-cooler to cool the FO membrane inlet streams (produced water feed streams with temperatures in excess of $25^{\circ} \mathrm{C}$ are assumed to require cooling prior to entering the FO membrane unit), gas contactor inlet streams, and to provide cooling duty for the gas contactor cooling system. The air-cooler is assumed to use fans for inducing the quantity of air flow required for efficient cooling performance. The air-cooler energy requirements are associated with the operation of these fans.

The cooling requirements calculated for the gas contactor and all other process operations that require air-cooling are summed to determine the total process cooling duty. The total cooling duty is input to an air-cooled condenser model (not included in process flow diagram pictures above) that computes the air flow rate and air-cooler fan power required. 
Process performance at off-design ambient temperatures was not evaluated as part of this analysis. It is anticipated that at elevated, off-design ambient temperature conditions the process efficiency will decrease as the corresponding increase in gas contactor operating temperature reduces the carbon dioxide solubility and $\mathrm{DMCAH}^{+}$and $\mathrm{HCO}_{3}{ }^{-}$equilibrium concentrations in the $\mathrm{FO}$ draw solution. Additional equilibrium and/or kinetic data for Reaction 4 is necessary to evaluate whether refrigeration or alternate cooling sources may be necessary for efficient process operation during times when air-cooling is unable to cool the gas contactor to the design temperature. Although it is possible that the membrane unit upper operating temperature limit could be reached during times of high ambient temperature, it is assumed that sizing the air-cooler for operation during these periods could adequately address this concern.

\subsection{Ancillary Process Equipment}

Assumed SPS FO process design point frictional pressure losses and heat exchanger minimum internal temperature approach values are specified in Table 3 and Table 4, respectively. Aspen Plus default efficiency values were used for rotational equipment such as pumps, fans, and compressors.

Table 3. SPS FO design point frictional pressure losses.

\begin{tabular}{|l|l|}
\hline Unit Operation/Process Piping Section & $\Delta \mathrm{P}_{\text {design }}$ (bar) \\
\hline FO membrane - permeate side & 0.2 \\
\hline degasser liquid product recuperator (cold side) & 0.3 \\
\hline degasser liquid product recuperator (hot side) & 0.3 \\
\hline degasser (reactor and vapor-liquid separator) & 0.4 \\
\hline mechanical separator inlet stream chiller & 0.3 \\
\hline degasser vapor product cooler & 0.3 \\
\hline degasser vapor product chiller & 0.3 \\
\hline gas contactor & 0.4 \\
\hline air-cooler outside bundle & $8.2 \times 10^{-4}$ \\
& $\left(0.33\right.$ in- $\left.\mathrm{H}_{2} \mathrm{O}\right)$ \\
\hline
\end{tabular}


Table 4. SPS FO design point heat exchanger minimum internal temperature approach (MITA) values.

\begin{tabular}{|l|l|}
\hline Heat exchanger & MITA $\left({ }^{\circ} \mathrm{C}\right)$ \\
\hline degasser heater (heat stream) & 5 \\
\hline degasser liquid product recuperator (MheatX) & 5 \\
\hline degasser vapor product cooler (MheatX) & 10 \\
\hline air-cooler (heat stream) & 10 \\
\hline
\end{tabular}

\section{RESULTS AND DISCUSSION}

The SPS FO water purification rate and product water quality are key process performance metrics. In general, the fraction of feed water purified is a function of the osmotic pressure differential between the feed and draw solutions.

Provided the SPS draw solution flow rate is sufficient to maintain an adequate osmotic pressure differential at the dilute end of a countercurrent flow path, the $77 \mathrm{wt} \% \mathrm{DMCAH}^{+}$and $\mathrm{HCO}_{3}{ }^{-}$draw solution upon which this analysis was based has sufficient osmotic pressure to concentrate an aqueous $\mathrm{NaCl}$ feed water stream to its saturation concentration. The fraction of the feed water stream purified is therefore determined by the quantity of water than can be removed before the saturation concentration is achieved $(6.14 \mathrm{~mol} / \mathrm{Kg})$. A plot of the fraction of water extracted from the $\mathrm{NaCl}$ aqueous feed stream is provided in Figure 4. This represents the maximum practical level of purification by FO process.

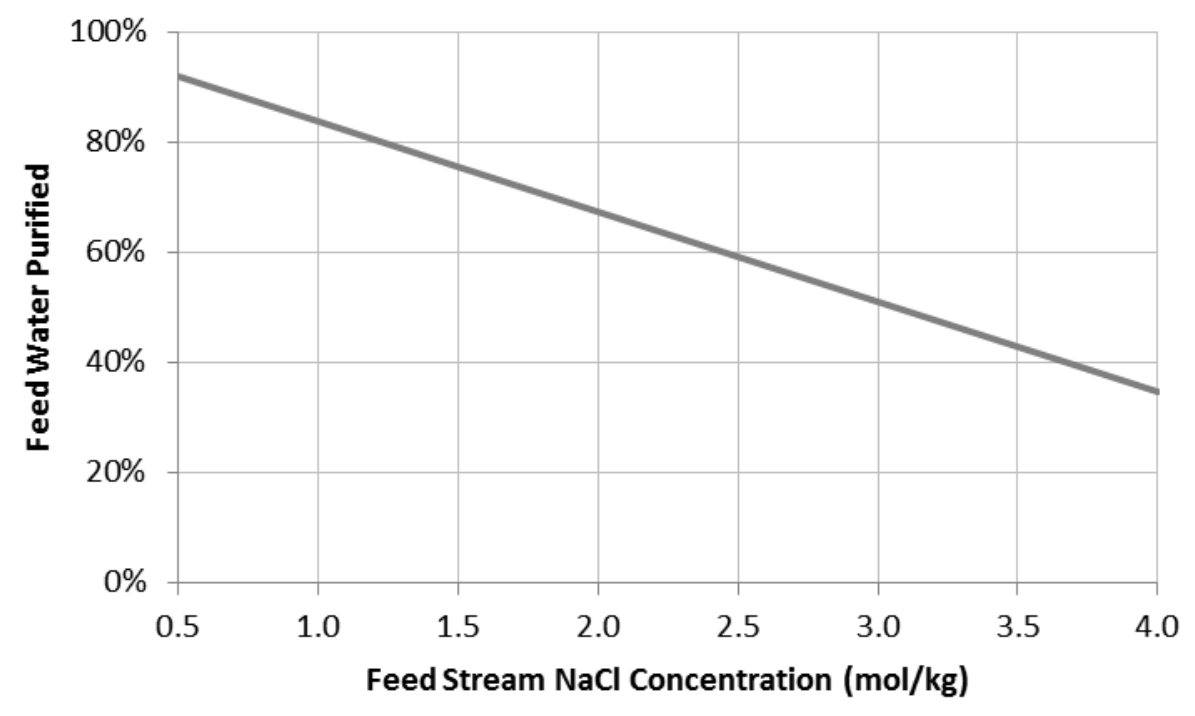

Figure 4. Percentage of feed water stream purified by SPS FO process. 
The SPS FO process model was used to analyze the energy requirements of the process. The SPS FO process requires both process heating and cooling for successful operation. It is worth noting that no energy requirements are directly attributable to the FO membrane unit or the mechanical (gravity) separator. Instead, the SPS FO process energy requirements are associated with fluid pumping and heating and cooling operations to achieve specified operating conditions and to drive the thermochemical processes which occur within the process.

Heat input is only required by the degasser for the purposes of increasing the temperature of the reactants to the specified operating temperature and for providing the heat of reaction required to drive the endothermic bicarbonate decomposition reaction. Conversely, process cooling is required for rejecting the exothermic heat of reaction from the bicarbonate formation reactions that occur in the gas contactor. Additional process cooling is required for temperature adjustment of the gas contactor vapor inlet stream, and the feed water stream. For a "cool" feed stream all or much of this cooling could be derived from the feed stream.

Mechanical energy is required to power SPS FO process mechanical operations including the dilute draw stream recycle pump, degasser liquid outlet pump, degasser vapor outlet compressor, and aircooler fan. This analysis assumes that electrical power is utilized for operation of these devices.

The SPS FO process energy requirements were evaluated as a function of feed water $\mathrm{NaCl}$ concentration and degasser operating temperature. The optimal degasser operating temperature required to drive the bicarbonate decomposition reaction near completion is still being investigated. However, the range of degasser operating temperatures is expected to be in the range of $60^{\circ} \mathrm{C}$ to $80^{\circ} \mathrm{C}$. The process energy requirements were evaluated at the upper and lower bounds of this range to determine the sensitivity to degasser operating temperature.

Process energy requirements are reported in terms of thermal or electrical energy required per cubic meter of purified water product, i.e. units of $\mathrm{kW}_{\mathrm{t}}-\mathrm{hr} / \mathrm{m}^{3}$ for process thermal energy requirements and $\mathrm{kW}_{\mathrm{e}}-\mathrm{hr} / \mathrm{m}^{3}$ for process electrical energy requirements. The SPS FO process thermal energy requirements 
are also presented in terms of electrical equivalent for thermal energy for purposes of comparing process total energy requirements with those of other desalination processes.

\subsection{Scenario 1: Process thermal energy input provided by external heat source}

Thermal energy requirements for the external heat source SPS FO process (Scenario 1) are presented in Figure 5. The required thermal energy input for the case with an $80^{\circ} \mathrm{C}$ degasser operating temperature is greater than for the $60^{\circ} \mathrm{C}$ degasser operating temperature case. The degasser inlet stream must be elevated to the specified operating temperature from a starting temperature of approximately $25^{\circ} \mathrm{C}$ in either case, so the greater energy requirements for the higher temperature process are expected.

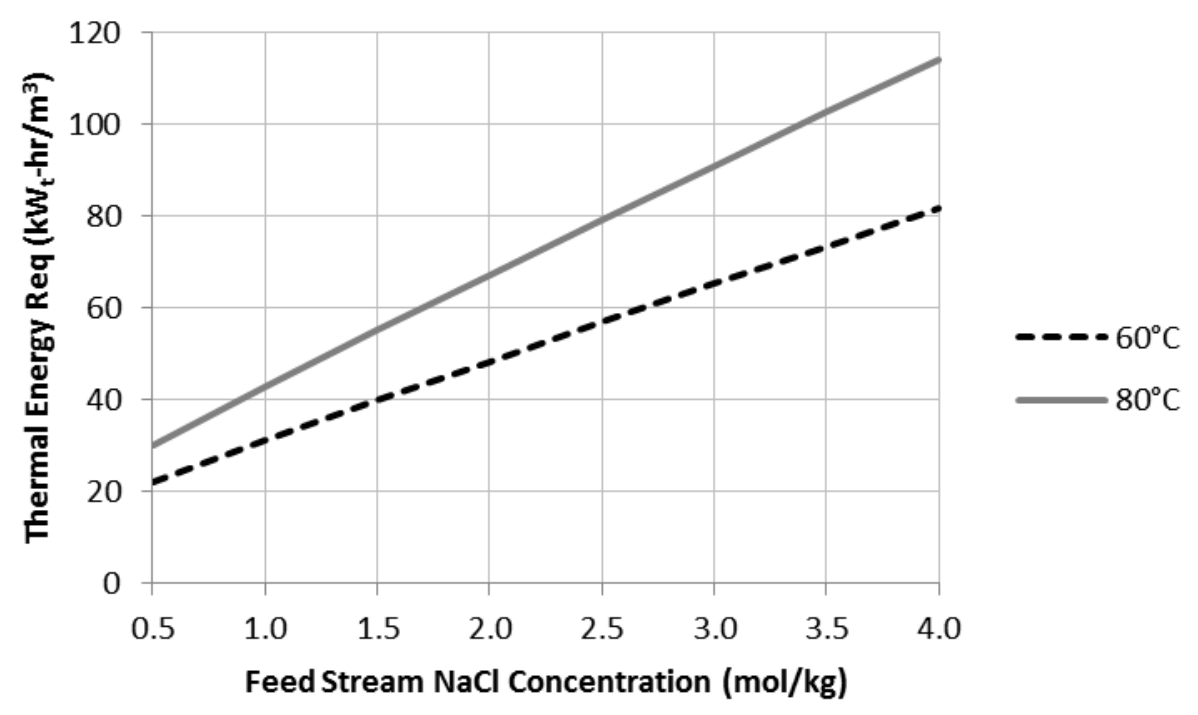

Figure 5. Thermal energy requirements of externally heated SPS FO process with $60^{\circ} \mathrm{C}$ and $80^{\circ} \mathrm{C}$ degasser operating temperatures.

Electrical energy requirements for the cases with $60^{\circ} \mathrm{C}$ and $80^{\circ} \mathrm{C}$ degasser operating temperatures are presented in Figure 6. The single largest electrical energy demand is associated with the compressor for both the $60^{\circ} \mathrm{C}$ and $80^{\circ} \mathrm{C}$ degasser operating temperature cases. The compressor energy requirements are greater for the $80^{\circ} \mathrm{C}$ case primarily due to the increased quantity of water vapor entrained with the $\mathrm{CO}_{2}$ exiting the degasser. Although the degasser operating pressure could be increased above the 0.8 bar (absolute pressure) set point utilized in this analysis, doing so would likely have the undesired effect of 
decreasing the completeness of the bicarbonate decomposition reactions. The compressor energy requirement is also a function of the frictional pressure losses elsewhere in the process, as the compressor is the device responsible for providing the motive force to the low pressure vapor stream required overcome these frictional losses. Any variations to the assumed process component pressure losses described in Table 3 will ultimately affect the process pumping and compression energy requirements.

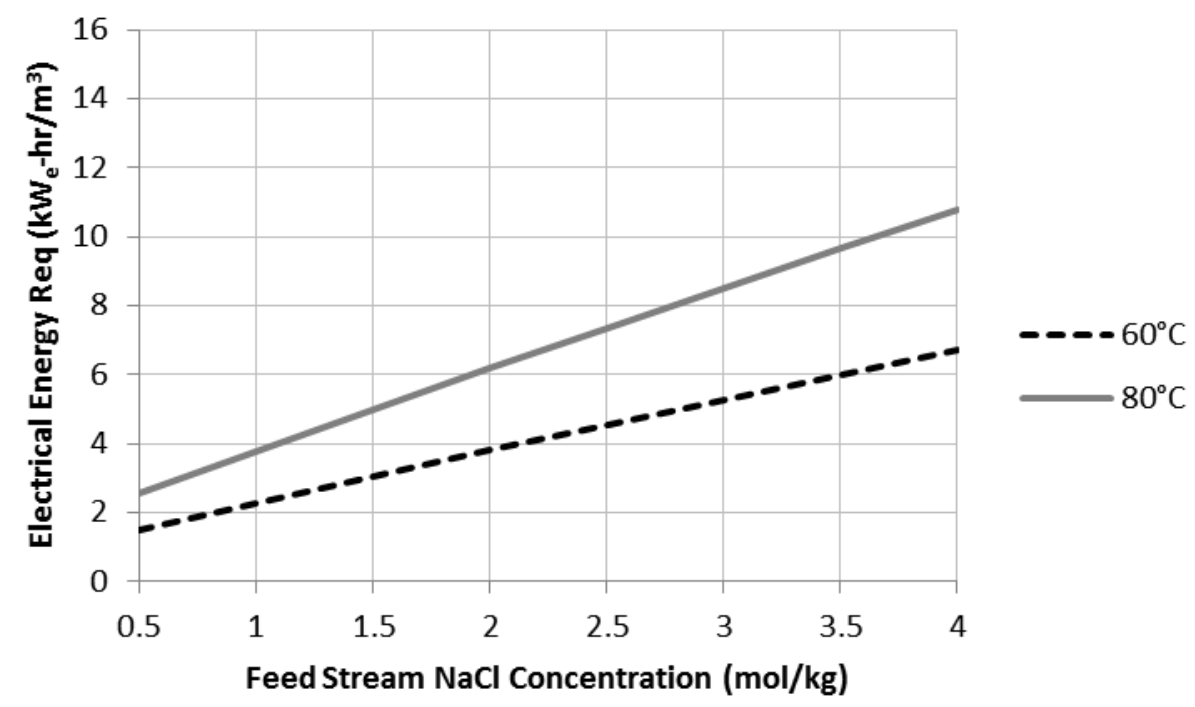

Figure 6. Electrical energy requirements of externally heated SPS FO process with $60^{\circ} \mathrm{C}$ and $80^{\circ} \mathrm{C}$ degasser operating temperatures.

It is apparent from Figure 5 and Figure 6 that the SPS FO process thermal and electrical energy demands increase as a function of the feed stream $\mathrm{NaCl}$ concentration $(\mathrm{NaCl}$ molality is directly proportional to the feed stream osmotic pressure). The concentrated draw solution stream flow rate initially increases with increasing feed stream $\mathrm{NaCl}$ concentration in order to maintain positive permeate flux at the dilute end of the membrane. At a feed stream $\mathrm{NaCl}$ concentration of approximately $3 \mathrm{~mol} / \mathrm{kg}$ the water flux through the membrane reaches a value where further increases in draw solution flow rate are not necessary, and positive flux can be maintained at lower concentrated draw solution flow rates. The concentrated draw solution flow rate required for saturation of the $\mathrm{NaCl}$ feed stream is plotted in Figure 7. While the net process energy requirements increase with draw solution flow rate due to increased pumping and heating and cooling requirements, the decrease in water permeate flux at higher feed stream $\mathrm{NaCl}$ concentrations results in a continued increase in energy requirements per unit water product despite 
the decrease in draw solution flow rate (and the corresponding decrease in the process net energy requirements, for which a figure is not provided).

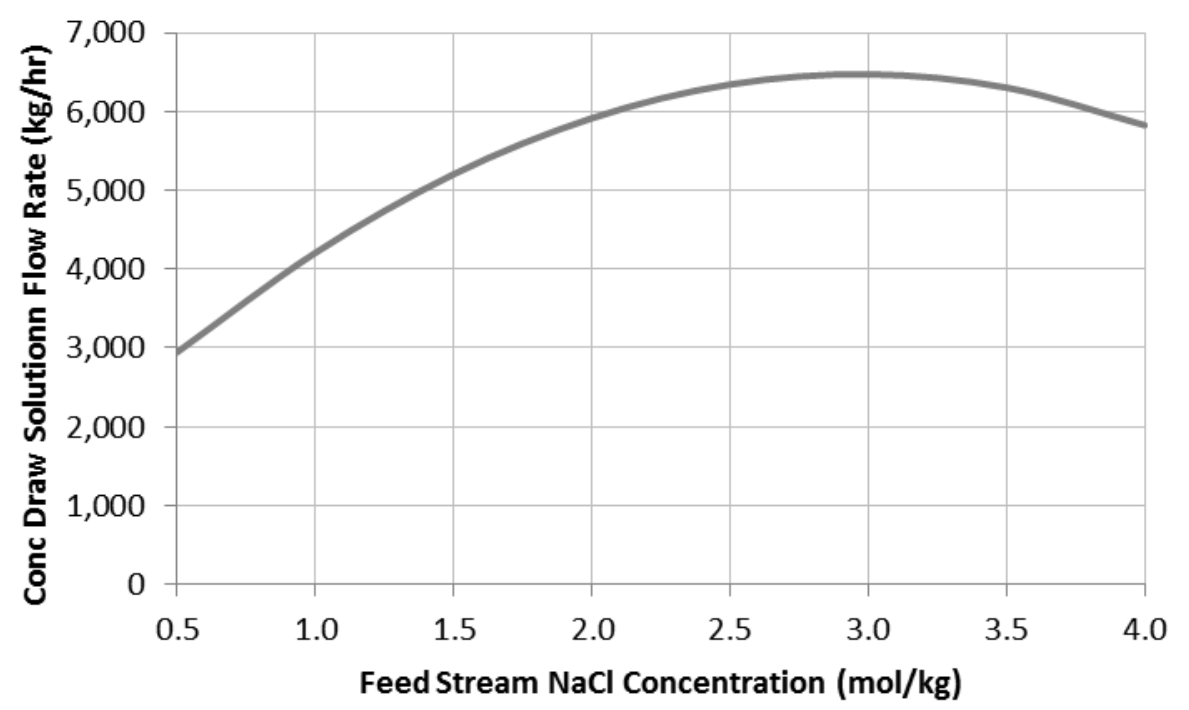

Figure 7. Concentrated draw solution stream flow rate required for saturation of $\mathrm{NaCl}$ feed stream.

\subsection{Scenario 2: Feed water stream is supplied at a temperature sufficient to provide the process thermal energy input}

The feed water heated SPS FO process configuration (Scenario 2) utilizes the thermal energy in the feed water stream to provide the process thermal energy requirements. This scenario would potentially be applicable if the SPS FO process were utilized to purify a produced water stream supplied at elevated temperature. The feed water temperature must be provided at a temperature in excess of the degasser operating temperature for successful heat transfer operations. This analysis assumes that the feed water stream exiting the degasser heat exchange operation must have an exit temperature $5^{\circ} \mathrm{C}$ greater than the operating temperature. The feed water stream is therefore required to have an inlet temperature sufficiently high to meet the degasser thermal energy demands while also meeting the exit temperature specification. Figure 8 summarizes the feed water inlet stream temperatures required to meet SPS FO process thermal energy demands. 


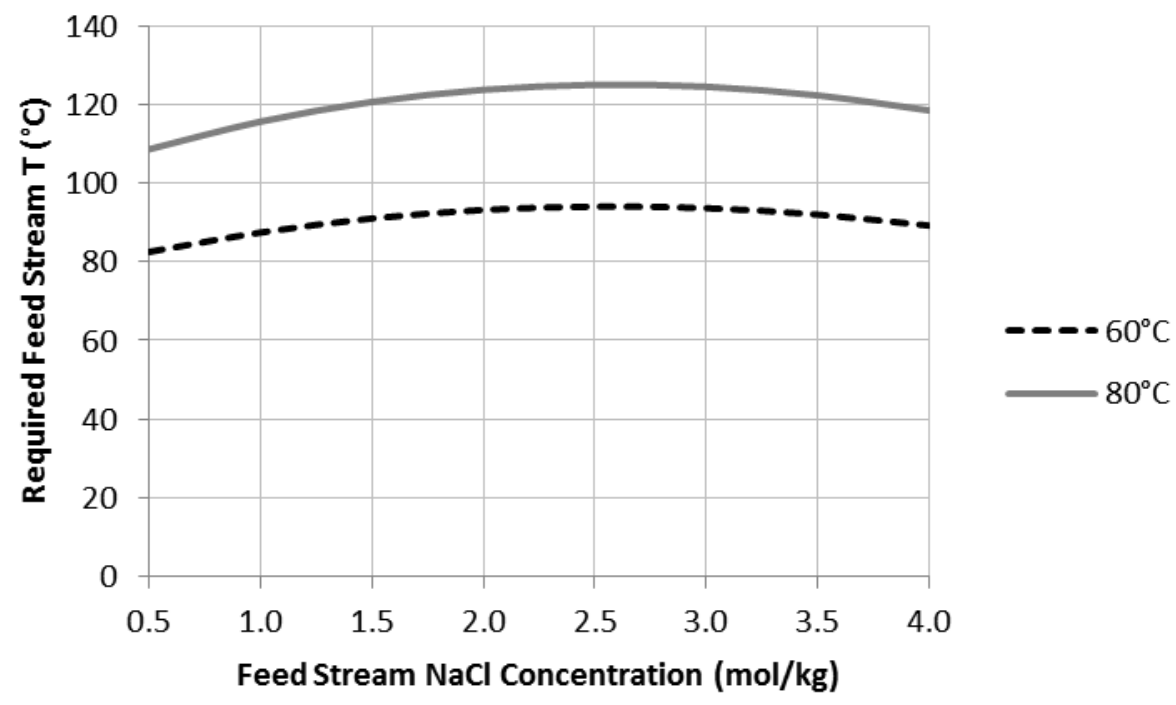

Figure 8. Required feed water temperature to provide SPS FO process thermal energy requirements.

The feed water heated SPS FO process configuration electrical energy requirements for the two degasser operating temperatures evaluated is presented in Figure 9. The SPS FO process electrical power requirements must be provided by an external power source in this scenario. The primary difference in energy requirements from the externally-heated SPS FO process (Scenario 1) is that additional air-cooler fan power is required for the feed water-heated process configuration. This is a result of the additional cooling that is required to adjust the feed water stream temperature to the specified FO membrane unit operating temperature of $25^{\circ} \mathrm{C}$ following the degasser heat exchange operation. 


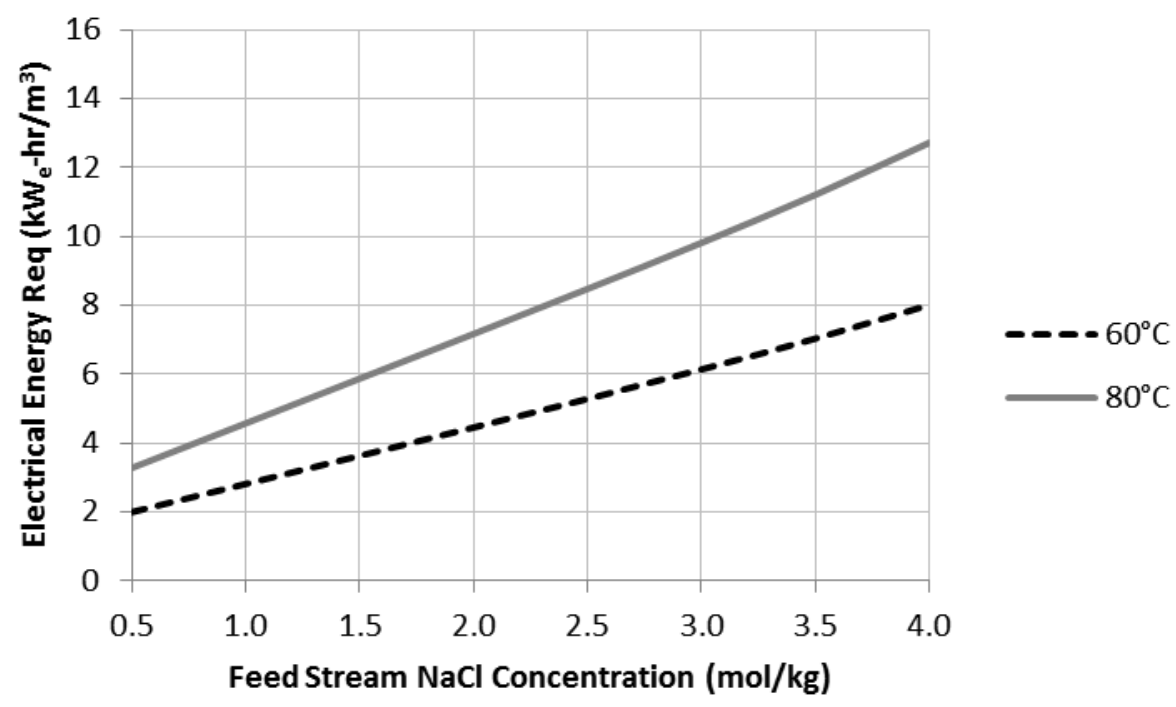

Figure 9. Electrical energy requirements of feed water heated SPS FO process with $60^{\circ} \mathrm{C}$ and $80^{\circ} \mathrm{C}$ degasser operating temperatures.

Figure 10 provides a breakdown of the feed water-heated SPS FO process cooling demands that determine the air-cooler energy requirements. As can be seen from these figures, the feed water cooling (post-degasser heat exchange operation) represents the largest process cooling requirement. The cooling requirements reported are referenced to each cubic meter of purified product water. The nonlinear increase in feed water cooling with increasing feed water $\mathrm{NaCl}$ concentration is attributed to the requirement that the entire feed stream be cooled to the specified FO membrane inlet temperature even though the fraction of the feed water stream that permeates the membrane decreases with $\mathrm{NaCl}$ concentration (see Figure 4). 


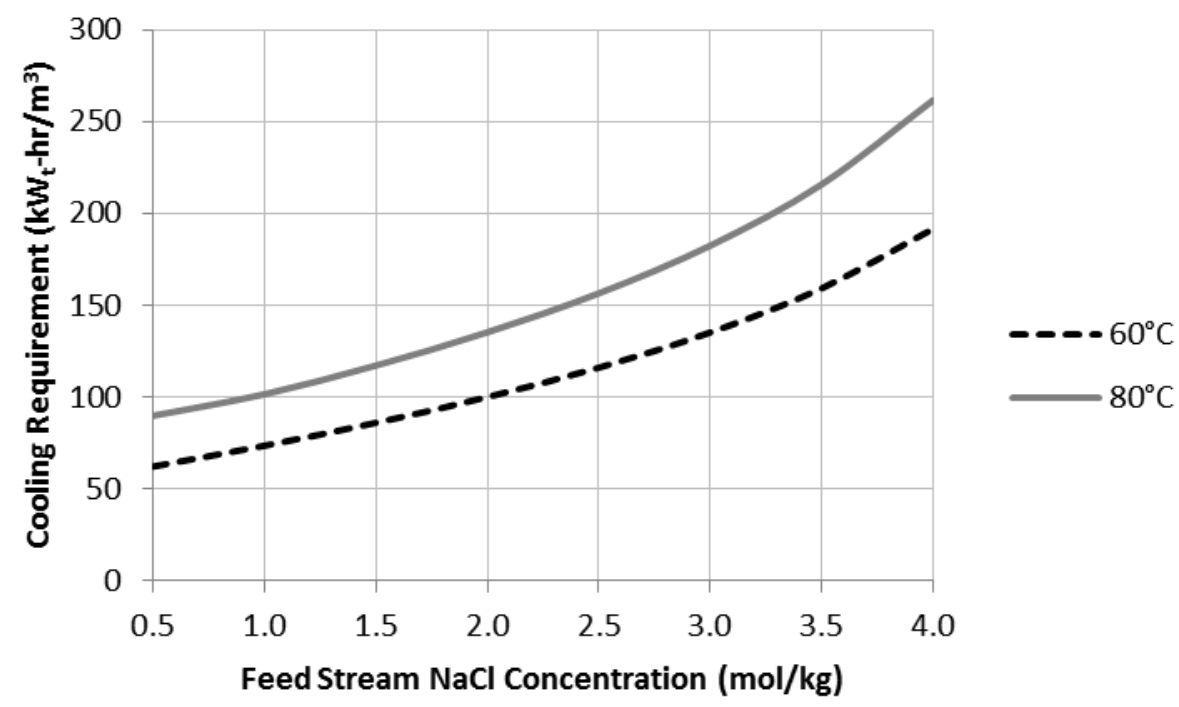

Figure 10. Process cooling requirements of feed water heated SPS FO process with $60^{\circ} \mathrm{C}$ and $80^{\circ} \mathrm{C}$ degasser operating temperatures.

\subsection{Scenario 3 (ORC/SPS FO): Feed water stream temperature is sufficient to provide heat} input to an ORC power cycle in addition to process thermal energy input

The ORC/SPS FO process configuration (Scenario 3) utilizes the thermal energy in the feed water stream to provide the process thermal energy requirements as well as to drive an ORC process that provides electrical power to the SPS FO process. As in Scenario 2, the feed water temperature must be provided at a temperature in excess of the degasser operating temperature for successful heat transfer operations. The thermal energy in the feed water stream is utilized to (1) vaporize the ORC working fluid, (2) input heat to SPS FO degasser, and (3) provide ORC working fluid preheating duty.

There are several advantages to the ORC/SPS FO coupled process. First, the feed water cooling requirements to meet the FO membrane unit inlet temperature specifications is lower than in Scenario 2 as a result of the ORC working fluid preheating operation (which reduces the feed water stream to a temperature lower than the degasser operating temperature). Second, the power generated by the ORC can offset of the SPS FO electrical power requirements. Figure 11 summarizes the net electrical energy 
production per cubic meter of purified water product as a function of feed stream $\mathrm{NaCl}$ concentration and feed stream supply temperature.

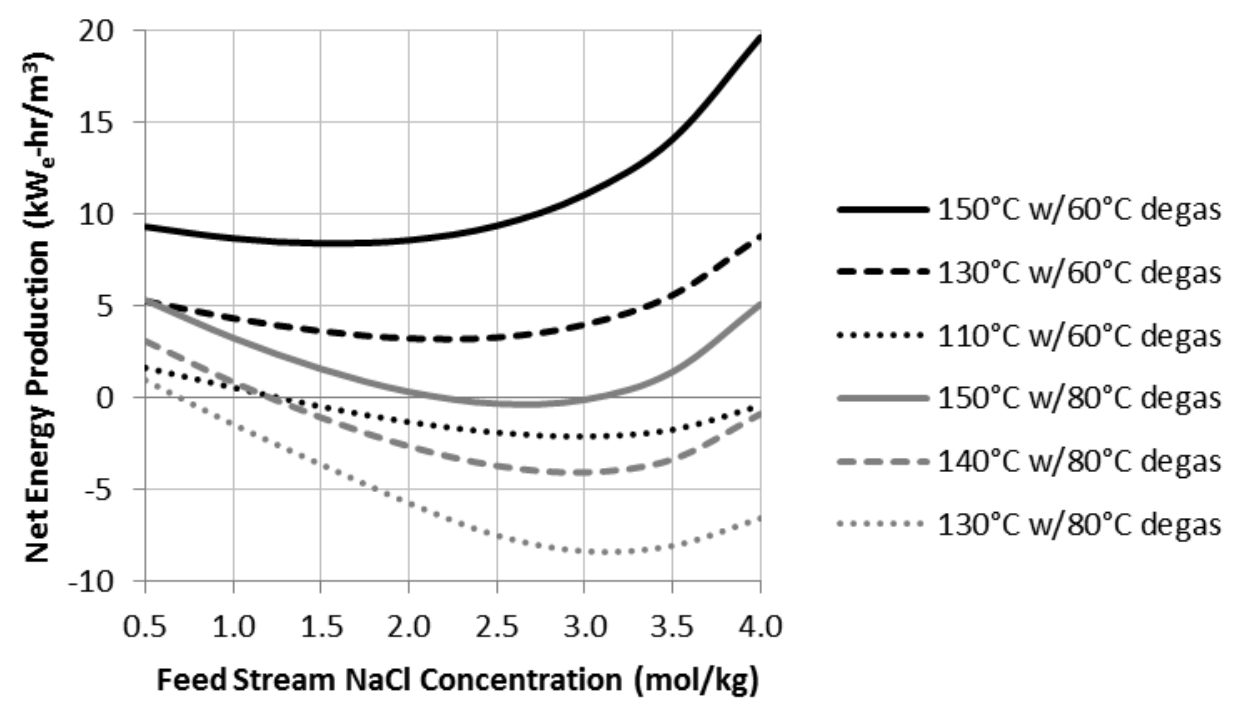

Figure 11. Net electrical energy production of ORC/SPS FO process for range of feed stream temperatures and degasser operating temperatures.

It is unlikely that the ORC and SPS FO processes would be coupled if the feed water temperature was insufficient for generation of positive net electrical power, since an external electrical power source would still be required. It is anticipated that if the ORC unit could not meet the electrical power demands of the SPS FO process it would be economically favorable to obtain electrical power from an external source. The feed stream temperatures chosen for the Scenario 3 analysis were selected to illustrate the range of conditions where the ORC/SPS FO would be practical.

For a degasser operating temperature of $60^{\circ} \mathrm{C}$, a $110^{\circ} \mathrm{C}$ feed stream with an $\mathrm{NaCl}$ concentration less than a 1.0 molal would contain sufficient thermal energy for positive net power generation. Feed water streams of $130^{\circ} \mathrm{C}$ and greater would provide sufficient thermal energy for positive net power generation over the range of $\mathrm{NaCl}$ concentrations evaluated.

For a degasser operating temperature of $80^{\circ} \mathrm{C}$, the ORC/SPS FO process operates with a positive net power generation for a more limited set of conditions. Feed water streams of $130^{\circ} \mathrm{C}$ may be processed with a positive net power generation when the feed stream $\mathrm{NaCl}$ concentration is less than approximately 
0.5 molal. A feed water stream temperature of $140^{\circ} \mathrm{C}$ will permit treatment of feed water streams of up to 1 molal $\mathrm{NaCl}$ concentration. Finally, a feed water stream temperature of $150^{\circ} \mathrm{C}$ will permit treatment of streams where the $\mathrm{NaCl}$ concentration is less than 1.75 molal or greater than 3.5 molal. The SPS FO energy requirements are greatest when the feed water stream concentration is in the range of approximately 1.5 to 3.5 molar due to the greater draw stream flow rate required to concentrate the feed water stream to saturation, as previously described. $\mathrm{An} \mathrm{NaCl}$ feed water stream supplied at a temperature of approximately $155^{\circ} \mathrm{C}$ contains sufficient thermal energy to operate the ORC/SPS FO process with a positive net power generation for feed water streams with up to 4 molal $\mathrm{NaCl}$ concentration. This analysis assumes a constant ambient temperature of $10^{\circ} \mathrm{C}$. At off-design operating conditions with elevated ambient temperatures, the power generation from the air-cooled ORC unit will decrease such that it may no longer be possible to meet SPS FO process electrical power demands as described above.

\subsection{Total energy requirements for SPS FO}

SPS FO process thermal energy requirements may be met with low grade thermal heat. The "equivalent work" for process thermal energy requirements was computed using the method utilized by McGinnis [19] for computing FO energy requirements for an ammonia-carbon dioxide system. The equivalent work calculation accounts for both the quantity and the grade of energy utilized by a thermal process. Addition of process equivalent work and electrical power requirements provides a comprehensive energy cost figure that can be used for comparing energy requirements of various water purification technologies via Equation 3 where, $H_{\text {steam used }}$ is the enthalpy of the steam used to provide process heat input, $\mathrm{H}_{\text {steam at condenser }}$ is the enthalpy of the steam at the condenser inlet (assumed $\mathrm{T}=35^{\circ} \mathrm{C}$ ), $\mathrm{E}_{\text {turbine }}$ is the turbine efficiency (assumed $\mathrm{E}_{\text {turbine }}=95 \%$ ), $\mathrm{W}_{\text {elec }}$ is the electrical power required by the process, GOR is the gain output ratio, GOR $=\frac{H_{\text {vap,steam }}(\mathrm{kJ} / \mathrm{kg})}{\text { Thermal energy for process }\left(\mathrm{MJ} / \mathrm{m}^{3}\right)}$, and $\mathrm{H}_{\text {vap,steam }}$ is the heat of vaporization of steam at the process heat input temperature. 


$$
W_{e q}=\frac{1000 \mathrm{~kg}_{\text {water product }}\left(H_{\text {steam used }}-H_{\text {steam at condenser }}\right) \times E_{\text {turbine }}}{G O R \times 3600 \frac{\mathrm{kJ}}{\mathrm{kWh}}}+W_{\text {elec }}
$$

Total equivalent energy consumption was computed for the SPS FO process assuming use of steam at $20^{\circ} \mathrm{C}$ in excess of the degasser operating temperature. In practice, however, the SPS FO process could be operated using thermal energy input from a low grade waste heat stream rather than steam. A steam thermal energy heat source is only utilized in these calculations for purposes of computing total equivalent energy requirements for comparison with alternate water treatment technologies. SPS FO process total equivalent energy consumption is summarized in Figure 12 for $60^{\circ} \mathrm{C}$ and $80^{\circ} \mathrm{C}$ degasser operating temperatures.

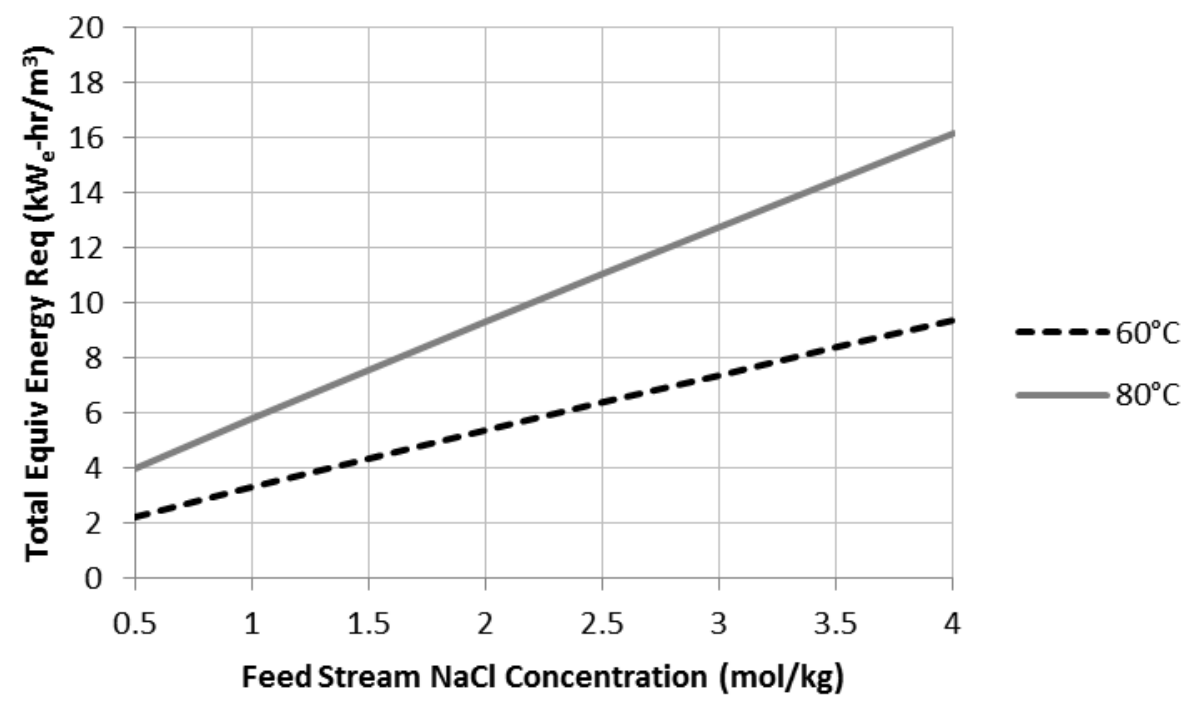

Figure 12. SPS FO Process Total Equivalent Energy Consumption with $60^{\circ} \mathrm{C}$ and $80^{\circ} \mathrm{C}$ degasser operating temperatures.

For desalination of seawater, which has an $\mathrm{NaCl}$ concentration of approximately $0.6 \mathrm{~mol} / \mathrm{kg}$, the SPS FO process has total equivalent energy consumption of approximately 2.4 to $4.3 \mathrm{kWh} / \mathrm{m}^{3}$ (depending on degasser operating temperature) for a $>90 \%$ water recovery. This compares favorably with industrial seawater RO processes which have electrical energy consumption in the range of $4-6 \mathrm{kWh} / \mathrm{m}^{3}$ for a $~ 50 \%$ water recovery (RO process energy requirements are primarily mechanical and/or electrical) and more demanding pretreatment regime. Based on this analysis, the SPS FO process significantly outperforms other desalination processes that utilize thermal energy with the capacity to treat high concentrations and 
recover high water fractions. Total equivalent energy consumption for alternate thermal desalination processes are reported as: $19.58-27.25 \mathrm{kWh} / \mathrm{m}^{3}$ for the Multi-stage Flash (MSF) process, 14.45-21.35 $\mathrm{kWh} / \mathrm{m}^{3}$ for the Multi-Effect Distillation (MED) process, $7-12 \mathrm{kWh} / \mathrm{m}^{3}$ for the Mechanical Vapor Compression (MVC) process, and $16.26 \mathrm{kWh} / \mathrm{m}^{3}$ for the Thermal Vapor Compression (TVC) process [23].

\subsection{Process Costs}

SPS FO capital and operating costs were estimated for Scenarios 1 through 3 described in sections 3.1 to 3.3 , respectively. Costs were estimated with a feed stream flow rate of $20 \mathrm{~m}^{3} / \mathrm{hr}$ and concentration of $0.6 \mathrm{~mol} / \mathrm{kg} \mathrm{NaCl}(33,900 \mathrm{ppm}$ TDS). A $0.6 \mathrm{~mol} / \mathrm{kg} \mathrm{NaCl}$ feed stream has a slightly lower TDS than seawater $(33,900 \mathrm{vs} \sim 35,000 \mathrm{ppm})$ and an osmotic concentration that is higher $(1.25 \mathrm{Osm} / \mathrm{kg}$ vs. $\sim 1.0 \mathrm{Osm} / \mathrm{Kg}$ ). Because the model osmotic concentration is higher any cost estimate using $0.6 \mathrm{~mol} / \mathrm{kg}$ $\mathrm{NaCl}$ is conservative versus seawater $[22,24]$. At this feed stream concentration, the SPS FO process produces $17.8 \mathrm{~m}^{3} / \mathrm{hr}$ of purified product water. Although the SPS FO process costs are expected to vary with feed stream concentration, the selected feed stream concentration is likely to be representative for desalination applications while also being illustrative for produced water treatment applications.

For membrane capital cost estimation a flux rate of $3.0 \mathrm{~L} / \mathrm{m}^{2}-\mathrm{hr}$ is assumed, a very conservative estimate based on a previous FO pilot system [25]. Degasser and gas contactor sizing was based on scaling of absorption and regeneration columns utilized for $\mathrm{CO}_{2}$ capture applications reported in the literature [26]. The scaling factor implemented was the ratio of the $\mathrm{CO}_{2}$ flow rate entering the SPS FO process gas contactor to the $\mathrm{CO}_{2}$ flow rate captured by the post-combustion capture (PCC) process. As the flow rate of $\mathrm{CO}_{2}$ handled by each of these processes varies by several orders of magnitude there is significant uncertainty in the accuracy of the SPS FO process equipment sizing calculations based on this approach. There are several important differences between these processes that result in significant uncertainty in the SPS FO degasser and gas contactor sizing. First, the post-combustion carbon capture 
process is designed to remove $\mathrm{CO}_{2}$ from a flue gas stream with approximately $10 \mathrm{~mol} \% \mathrm{CO}_{2}$ while the SPS FO gas contactor stream would be composed primarily of $\mathrm{CO}_{2}$ (some water vapor would also be present). These significant inlet stream composition differences would undoubtedly affect the performance of the SPS FO gas contactor relative to that of the $\mathrm{PCC} \mathrm{CO}_{2}$ absorption column. Second, PCC carbon capture processes typically use amine solutions composed primarily of primary and/or secondary amines, which are generally characterized by more rapid reaction kinetics than tertiary amines. As the SPS FO gas contactor vapor inlet stream is composed primarily of $\mathrm{CO}_{2}$ and has a comparatively small flow rate it would be possible to manipulate the compressor outlet pressure to optimize the gas contactor performance. The increased $\mathrm{CO}_{2}$ partial pressure in the SPS gas contactor (and the associated increases in liquid phase $\mathrm{CO}_{2}$ concentration) relative to PCC carbon capture should partially compensate for the reduced reaction rate typical of tertiary amines.

Installed capital costs for the remaining process equipment were obtained using Aspen Process Economic Analyzer V8.4 with input of the major process equipment size parameters. Installed capital costs are presented in Table 5 in thousands of US Dollars indexed to year 2014. 
Table 5. Installed Capital Costs of SPS FO process for purification of $20 \mathrm{~m}^{3} / \mathrm{hr}$ of $0.6 \mathrm{~mol} / \mathrm{kg} \mathrm{NaCl}(34.6$ g/L TDS) feed water stream.

\begin{tabular}{|c|c|c|c|c|c|c|}
\hline Cost in 2014 USD (thousands) & \multicolumn{2}{|c|}{$\begin{array}{l}\text { Scenario 1: } \\
\text { low temperature feed } \\
\text { stream }\end{array}$} & \multicolumn{2}{|c|}{$\begin{array}{l}\text { Scenario 2: } \\
\text { intermediate } \\
\text { temperature feed } \\
\text { stream }\end{array}$} & \multicolumn{2}{|c|}{$\begin{array}{l}\text { Scenario 3: } \\
\text { elevated temperature } \\
\text { feed stream }\end{array}$} \\
\hline Scenario description & \multicolumn{2}{|c|}{$\begin{array}{l}\text { external thermal and } \\
\text { electrical energy } \\
\text { sources required }\end{array}$} & \multicolumn{2}{|c|}{$\begin{array}{l}\text { process thermal } \\
\text { energy input supplied } \\
\text { by feed stream }\end{array}$} & \multicolumn{2}{|c|}{$\begin{array}{l}\text { process thermal and } \\
\text { electrical energy } \\
\text { requirements } \\
\text { provided by feed } \\
\text { stream }\end{array}$} \\
\hline degasser temperature & $60^{\circ} \mathrm{C}$ & $80^{\circ} \mathrm{C}$ & $60^{\circ} \mathrm{C}$ & $80^{\circ} \mathrm{C}$ & $60^{\circ} \mathrm{C}$ & $80^{\circ} \mathrm{C}$ \\
\hline feed stream filter & $\$ 23$ & $\$ 23$ & $\$ 23$ & $\$ 23$ & $\$ 23$ & $\$ 23$ \\
\hline FO membrane unit & $\$ 363$ & $\$ 363$ & $\$ 363$ & $\$ 363$ & $\$ 363$ & $\$ 363$ \\
\hline dilute SPS recycle pump & $\$ 28$ & $\$ 28$ & $\$ 28$ & $\$ 28$ & $\$ 28$ & $\$ 28$ \\
\hline degasser liquid product pump & $\$ 37$ & $\$ 37$ & $\$ 37$ & $\$ 37$ & $\$ 37$ & $\$ 37$ \\
\hline degasser preheater & $\$ 158$ & $\$ 213$ & $\$ 158$ & $\$ 213$ & $\$ 158$ & $\$ 213$ \\
\hline degasser heater & $\$ 254$ & $\$ 279$ & $\$ 144$ & $\$ 158$ & $\$ 144$ & $\$ 158$ \\
\hline degasser & $\$ 96$ & $\$ 96$ & $\$ 96$ & $\$ 96$ & $\$ 96$ & $\$ 96$ \\
\hline gas contactor & $\$ 367$ & $\$ 367$ & $\$ 367$ & $\$ 367$ & $\$ 367$ & $\$ 367$ \\
\hline compressor & $\$ 498$ & $\$ 580$ & $\$ 498$ & $\$ 580$ & $\$ 498$ & $\$ 580$ \\
\hline compressor exhaust HX & $\$ 68$ & $\$ 72$ & $\$ 68$ & $\$ 72$ & $\$ 68$ & $\$ 72$ \\
\hline air-cooler & $\$ 93$ & $\$ 95$ & $\$ 159$ & $\$ 201$ & $\$ 141$ & $\$ 171$ \\
\hline mechanical separator & $\$ 259$ & $\$ 259$ & $\$ 259$ & $\$ 259$ & $\$ 259$ & $\$ 259$ \\
\hline total installed capital cost* & $\$ 2,244$ & $\$ 2,412$ & $\$ 2,200$ & $\$ 2,397$ & $\$ 2,182$ & $\$ 2,367$ \\
\hline
\end{tabular}

* ORC costs not included in capital cost estimate

The primary operating costs are associated with the process heating costs (Scenario 1 only)

process electrical power requirements (Scenarios 1 and 2 only) and membrane replacement costs.

External process heating costs for Scenario 1 are calculated assuming a natural gas purchase price of

$\$ 5 / \mathrm{Mcf}$ (\$177 per thousand cubic meters). Electricity costs are calculated assuming a purchase price of

$\$ 0.08 / \mathrm{kWh}$. The FO membranes are expected to require replacement every five years; the annual

operating cost estimate therefore includes a 20\% annual FO replacement cost. The DMCA and $\mathrm{CO}_{2}$

replacement costs are expected to be small and are therefore not included in the annual operating cost

estimate.

Estimated SPS FO process annual operating costs are presented in Table 6. Estimated operating costs assume continuous process operation with no down time. The purified water product stream flow 
rate was calculated as $17.8 \mathrm{~m}^{3} / \mathrm{hr}$ (independent of degasser operating temperature), resulting in an annual purified water product volume of $156,000 \mathrm{~m}^{3}$ if the continuous process operation assumption is upheld.

Table 6. Estimated annual operating costs of SPS FO process for purification of $20 \mathrm{~m}^{3} / \mathrm{hr}$ of $0.6 \mathrm{~mol} / \mathrm{kg}$ $\mathrm{NaCl}$ (34.6 g/L TDS) feed water stream.

\begin{tabular}{|l|r|r|r|r|r|r|}
\hline & \multicolumn{3}{|l|}{ Scenario 1 } & \multicolumn{2}{l|}{ Scenario 2 } & \multicolumn{2}{l|}{ Scenario 3 } \\
\hline degasser temperature & $60^{\circ} \mathrm{C}$ & $80^{\circ} \mathrm{C}$ & $60^{\circ} \mathrm{C}$ & $80^{\circ} \mathrm{C}$ & $60^{\circ} \mathrm{C}$ & $80^{\circ} \mathrm{C}$ \\
\hline $\begin{array}{l}\text { FO membrane } \\
\text { replacement }\end{array}$ & $\$ 72,600$ & $\$ 72,600$ & $\$ 72,600$ & $\$ 72,600$ & $\$ 72,600$ & $\$ 72,600$ \\
\hline electrical power & $\$ 20,700$ & $\$ 34,900$ & $\$ 26,900$ & $\$ 44,100$ & N/A & N/A \\
\hline process heating & $\$ 62,000$ & $\$ 84,300$ & N/A & N/A & N/A & N/A \\
\hline $\begin{array}{l}\text { other }(1 \% \text { of capital } \\
\text { costs for labor, etc.) }\end{array}$ & $\$ 22,400$ & $\$ 24,100$ & $\$ 22,000$ & $\$ 24,000$ & $\$ 21,800$ & $\$ 23,600$ \\
\hline $\begin{array}{l}\text { total annual operating } \\
\text { costs }\end{array}$ & $\$ 177,700$ & $\$ 215,900$ & $\$ 121,500$ & $\$ 140,700$ & $\$ 94,400$ & $\$ 96,200$ \\
\hline
\end{tabular}

\subsection{Economic Assessment}

A basic economic assessment was performed to assess the economic viability of an SPS FO system that processes $20 \mathrm{~m}^{3} / \mathrm{hr}$ of $0.6 \mathrm{~mol} / \mathrm{kg} \mathrm{NaCl}$ feed water to yield $17.8 \mathrm{~m}^{3} / \mathrm{hr}$ of product water. The economic assessment utilized the process capital and operating costs reported in the previous section with an assumed capital recovery factor of $10 \%$ to estimate the costs for purification of a unit volume of feed water. Purified water product costs were computed for SPS FO process configurations corresponding to those described in Scenarios 1 through 3. The purified water product costs were then compared with reported disposal costs typical for produced waters.

Annual revenues required to both recover the initial capital investment and meet operating costs ranged from $\$ 312 \mathrm{~K}$ to $\$ 402 \mathrm{~K}$ for $60^{\circ} \mathrm{C}$ degasser operating temperature and $\$ 333 \mathrm{~K}$ to $\$ 457 \mathrm{~K}$ for $80^{\circ} \mathrm{C}$ degasser operating temperature. The value of the water product (sale price, offset of disposal price, or a combination thereof) would need to be higher than 2.00 to $2.58 \mathrm{USD} / \mathrm{m}^{3}\left(60^{\circ} \mathrm{C}\right.$ degasser $)$ or 2.13 to 2.93 $\mathrm{USD} / \mathrm{m}^{3}\left(80^{\circ} \mathrm{C}\right.$ degasser) for the SPS FO process operation to be viable at the system size evaluated. Most of this cost per unit water is based on the capital cost which would decline as the system size increased and the pay off period was extended. Costs at the high end of these ranges correspond to Scenario 1, 
where fuel must be purchased to provide the thermal energy required to operate the process. Conversely, the lower end costs correspond to Scenario 3, in which the feed water stream temperature is sufficient to provide heat input to an ORC power cycle in addition to process thermal energy input (electricity generated in power cycle used to power SPS FO process; excess electrical power sales not accounted for in this evaluation).

Throughout the US, there is considerable variability in both the cost of potable water and in the cost to dispose of produced waters. Average US residential water costs are often estimated at $\sim 0.50$ $\mathrm{USD} / \mathrm{m}^{3}$. Costs can be significantly higher depending of the geographic supply and metropolitan demand. The San Diego County Water Authority has agreed to buy at least 60 million cubic meters of water per year from the Carlsbad desalination plant for the next 30 years at $\sim 1.6 \mathrm{USD} / \mathrm{m}^{3}$. Although the Carlsbad price for water includes profit and other costs, the cost is similar to the cost modeled for a small scale SPS FO system dewatering a $0.6 \mathrm{~mol} / \mathrm{kg} \mathrm{NaCl}$ solution even though Carlsbad is a significantly larger scale with a longer paydown. In terms of produced water the primary concern is disposal. The Argonne National Laboratory report "Offsite Commercial Disposal of Oil and Gas Exploration and Production Waste: Availability, Options, and Cost" indicates disposal costs for produced waters can vary from 0.30 to $105 \mathrm{USD} / \mathrm{bbl}\left(1.88\right.$ to $\left.660 \mathrm{USD} / \mathrm{m}^{3}\right)$ depending on disposal method, which may include injection, evaporation, and burial. Injection is the most common means of disposal, with costs ranging from 0.30 $\mathrm{USD} / \mathrm{bbl}\left(1.88 \mathrm{USD} / \mathrm{m}^{3}\right)$ to as high as $10.00 \mathrm{USD} / \mathrm{bbl}\left(62.90 \mathrm{USD} / \mathrm{m}^{3}\right)$; generally the injection costs are under 1.00 USD/bbl $\left(6.30 \mathrm{USD} / \mathrm{m}^{3}\right)$ [27]. These costs would suggest that their avoidance significantly impacts the economic feasibility of the proposed SPF-FO technology application. When combined with the potential revenues from the sale of the product water, the economic feasibility is further enhanced.

There are also potential applications within conventional geothermal facilities which have yet to be evaluated. These applications could impact the water consumption in those facilities using evaporative cooling systems, and possible extend the use of evaporative cooling to plants that would otherwise be forced to use air-cooling because of the scarcity of water. This could be especially important to low 
temperature applications where the impact of the high ambient temperatures on performance make it difficult to justify a project.

\section{CONCLUSION}

Process energy requirements were presented for scenarios in which (1) the required process heat is provided by an external heat source, (2) the feed water stream is supplied at a temperature sufficient to provide the process thermal energy input, and (3) the feed water stream temperature is sufficient to provide process thermal energy input as well as to provide heat input to an organic Rankine cycle (ORC) power conversion cycle for meeting process electrical power requirements.

The total equivalent energy requirement of the SPS FO process for seawater desalination applications was determined to be in the range from 2.4 to $4.3 \mathrm{kWh} / \mathrm{m}^{3}$ (depending on degasser operating temperature) to dewater the solution to saturation (>90\% water recovery). Seawater Reverse Osmosis, which is the next most energy efficient desalination process, has electrical energy requirements in the range of 4 to $6 \mathrm{kWh} / \mathrm{m}^{3}$ for a $\sim 50 \%$ water recovery

\section{ACKNOWLEDGEMENTS}

This work was supported by the United States Department of Energy through contract DE-AC0705ID14517. Funding was supplied by the Department of Energy (DOE) Office of Energy Efficiency and Renewable Energy (EERE) Geothermal Technologies Office (GTO).

\section{REFERENCES}

[1] P.G. Jessop, D.J. Heldebrant, X. Li, C.A. Eckert, C.L. Liotta, Green chemistry: Reversible nonpolar-to-polar solvent, Nature. 436 (2005) 1102. doi:10.1038/4361102a.

[2] P.G. Jessop, L. Kozycz, Z.G. Rahami, D. Schoenmakers, A.R. Boyd, D. Wechsler, et al., Tertiary amine solvents having switchable hydrophilicity, Green Chem. 13 (2011) 619-623. doi:10.1039/C0GC00806K.

[3] P.G. Jessop, S.M. Mercer, D.J. Heldebrant, CO2-triggered switchable solvents, surfactants, and other materials, Energy Environ. Sci. 5 (2012) 7240-7253. doi:10.1039/C2EE02912J. 
[4] M.L. Stone, C. Rae, F.F. Stewart, A.D. Wilson, Switchable polarity solvents as draw solutes for forward osmosis, Desalination. 312 (2013) 124-129. doi:10.1016/j.desal.2012.07.034.

[5] James E. Miller, Lindsey R. Evans, SAND2006-4634 Forward Osmosis: A New Approach to Water Purification and Desalination, Sandia National Laboratory, 2006.

[6] J.R. McCutcheon, R.L. McGinnis, M. Elimelech, A novel ammonia--carbon dioxide forward (direct) osmosis desalination process, Desalination. 174 (2005) 1-11. doi:10.1016/j.desal.2004.11.002.

[7] Y. Cai, W. Shen, R. Wang, W.B. Krantz, A.G. Fane, X. Hu, CO2 switchable dual responsive polymers as draw solutes for forward osmosis desalination, Chem. Commun. 49 (2013) 8377-8379. doi:10.1039/C3CC43289K.

[8] Q. Zhao, N. Chen, D. Zhao, X. Lu, Thermoresponsive Magnetic Nanoparticles for Seawater Desalination, ACS Appl. Mater. Interfaces. 5 (2013) 11453-11461. doi:10.1021/am403719s.

[9] A. Zhou, H. Luo, Q. Wang, L. Chen, T.C. Zhang, T. Tao, Magnetic thermoresponsive ionic nanogels as novel draw agents in forward osmosis, RSC Adv. 5 (2015) 15359-15365. doi:10.1039/C4RA12102C.

[10] D. Li, H. Wang, Smart draw agents for emerging forward osmosis application, J. Mater. Chem. A. 1 (2013) 14049-14060. doi:10.1039/C3TA12559A.

[11] R. Ou, Y. Wang, H. Wang, T. Xu, Thermo-sensitive polyelectrolytes as draw solutions in forward osmosis process, Desalination. 318 (2013) 48-55. doi:10.1016/j.desal.2013.03.022.

[12] J. Kim, J.-S. Chung, H. Kang, Y. Yu, W. Choi, H. Kim, et al., Thermo-responsive copolymers with ionic group as novel draw solutes for forward osmosis processes, Macromol. Res. 22 (2014) 963970. doi:10.1007/s13233-014-2142-6.

[13] D. Zhao, S. Chen, P. Wang, Q. Zhao, X. Lu, A Dendrimer-Based Forward Osmosis Draw Solute for Seawater Desalination, Ind. Eng. Chem. Res. 53 (2014) 16170-16175. doi:10.1021/ie5031997.

[14] C. Boo, Y.F. Khalil, M. Elimelech, Performance evaluation of trimethylamine-carbon dioxide thermolytic draw solution for engineered osmosis, Journal of Membrane Science. 473 (2015) 302 309. doi:10.1016/j.memsci.2014.09.026.

[15] A.D. Wilson, F.F. Stewart, Structure-function study of tertiary amines as switchable polarity solvents, RSC Adv. 4 (2014) 11039-11049. doi:10.1039/C3RA47724J.

[16] A.D. Wilson, C.J. Orme, Concentration dependent speciation and mass transport properties of switchable polarity solvents, RSC Adv. 5 (2015) 7740-7751. doi:10.1039/C4RA08558B.

[17] C.J. Orme, A.D. Wilson, 1-Cyclohexylpiperidine as a thermolytic draw solute for osmotically driven membrane processes, Desalination. 371 (2015) 126-133. doi:10.1016/j.desal.2015.05.024.

[18] J.S. McNally, B. Noll, C.J. Orme, A.D. Wilson, Density Functional Theory Analysis of the Impact of Steric Interaction on the Function of Switchable Polarity Solvents, J. Phys. Chem. B. 119 (2015) 6766-6775. doi:10.1021/acs.jpcb.5b03167.

[19] R.L. McGinnis, M. Elimelech, Energy requirements of ammonia-carbon dioxide forward osmosis desalination, Desalination. 207 (2007) 370-382.

[20] M.A. Engle, I.M. Cozzarelli, B.D. Smith, USGS investigations of water produced during hydrocarbon reservoir development, U.S. Geological Survey, Reston, VA, 2014. http://pubs.er.usgs.gov/publication/fs20143104 (accessed March 30, 2015).

[21] Yudy Halim Tan, Study of CO2-absorption into thermomorphic lipophilic amine solvents, Technischen Universität Dortmund, 2010. https://eldorado.tu-dortmund.de/handle/2003/27427 (accessed February 26, 2014).

[22] A.D. Wilson, F.F. Stewart, Deriving osmotic pressures of draw solutes used in osmotically driven membrane processes, Journal of Membrane Science. 431 (2013) 205-211. doi:10.1016/j.memsci.2012.12.042.

[23] A. Al-Karaghouli, L.L. Kazmerski, Energy consumption and water production cost of conventional and renewable-energy-powered desalination processes, Renewable and Sustainable Energy Reviews. 24 (2013) 343-356. doi:10.1016/j.rser.2012.12.064. 
[24] K.K. Reimund, J.R. McCutcheon, A.D. Wilson, Thermodynamic analysis of energy density in pressure retarded osmosis: The impact of solution volumes and costs, Journal of Membrane Science. 487 (2015) 240-248. doi:10.1016/j.memsci.2015.03.076.

[25] R.L. McGinnis, N.T. Hancock, M.S. Nowosielski-Slepowron, G.D. McGurgan, Pilot demonstration of the $\mathrm{NH} 3 / \mathrm{CO} 2$ forward osmosis desalination process on high salinity brines, Desalination. 312 (2013) 67-74. doi:10.1016/j.desal.2012.11.032.

[26] Dale A. Jones, Tom F. McVey, S. Julio Friedmann, Technoeconomic Evaluation of MEA versus Mixed Amines for CO2 Removal at Near-Commercial Scale at Duke Energy Gibson 3 Plant, Lawrence Livermore National Laboratory, 2012. https://e-reports-ext.llnl.gov/pdf/700272.pdf (accessed October 23, 2014).

[27] J.A.V. M. G. Puder, Offsite commercial disposal of oil and gas exploration and production waste: availability, options, and cost., Argonne National Laboratory, 2006. 


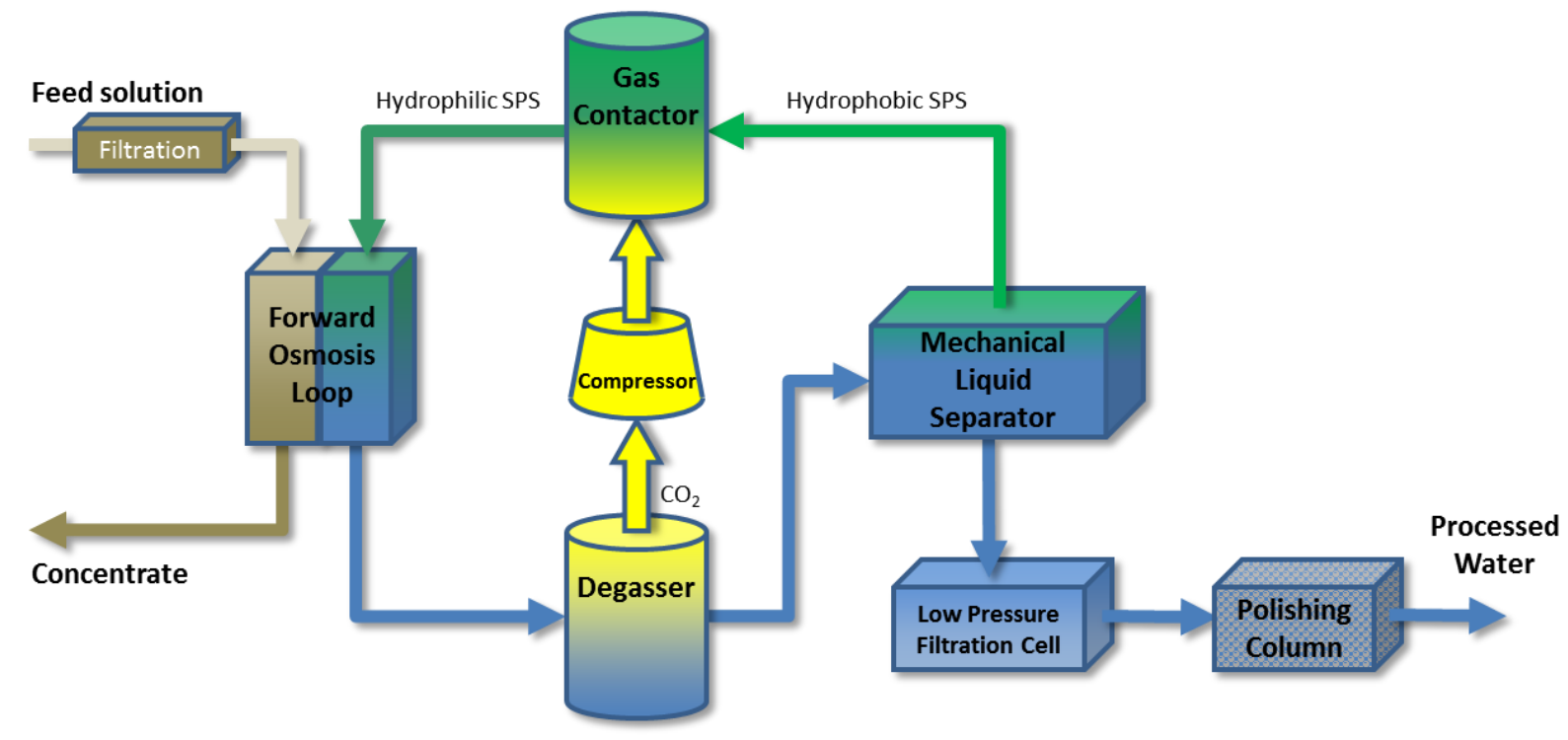

Graphical abstract 